\title{
Chromosomal analysis of non-small-cell lung cancer by multicolour fluorescent in situ hybridisation
}

\author{
HK Berrieman ${ }^{1,2}$, JNE Ashman ${ }^{1,2}$, ME Cowen $^{3}$, J Greenman ${ }^{1,2}$, MJ Lind ${ }^{1,2}$ and L Cawkwell ${ }^{*, 1,2}$ \\ 'Postgraduate Medical Institute, University of Hull, Cottingham Rd, Hull HU6 7RX, UK; ${ }^{2}$ Hull York Medical School, University of Hull, Cottingham Rd, Hull \\ HU6 7RX, UK; ${ }^{3}$ Cardiothoracic Unit, Castle Hill Hospital, Hull HUI6 5JQ, UK
}

Lung cancer is the biggest cause of cancer mortality in the world and has one of the worst survival rates of any solid tumour. Around $75-80 \%$ of all cases of lung cancer diagnosed are nonsmall-cell lung cancer (NSCLC). Although our knowledge of the events involved in NSCLC at the gene level is increasing, little is known about the gross structural chromosomal changes involved in the disease, in common with the majority of solid tumours. This is due to the extreme difficulty in obtaining metaphase spreads of sufficient quality and quantity for cytogenetic analysis. Interpretation of the complex genomes characteristic of solid tumours is also technically difficult using conventional cytogenetic banding methods. Conversely, studies of haematological malignancies have identified specific chromosomal abnormalities that have proved to be of diagnostic and prognostic value (Mitelman, 2000).

Recently developed molecular cytogenetic techniques have increased the potential for karyotypic analysis of solid tumour samples. Comparative genomic hybridisation (CGH) allows screening of the entire genome in order to identify regions of gain or loss of DNA and map them according to chromosomal location (Kallioniemi et al, 1992). A major advantage of CGH is that tissue culture and preparation of metaphase spreads is not required as DNA extracted from a tumour specimen is used.

*Correspondence: Dr L Cawkwell, R\&D Building, Castle Hill Hospital, Hull HUI6 5JQ, UK; E-mail: L.Cawkwell@hull.ac.uk

Received 17 April 2003; revised 7 October 2003; accepted 30 October 2003
Previous CGH studies of NSCLC cell lines and primary tumours have identified chromosomal regions that are commonly over- or under-represented, including gains of $1 \mathrm{q}, 3 \mathrm{q}, 5 \mathrm{p}, 7 \mathrm{p}$ and $8 \mathrm{q}$ and losses of 3p, 6q, 8p, 9p and 17p (Balsara et al, 1997; Petersen et al, 1997; Björkqvist et al, 1998; Speicher et al, 2000; Luk et al, 2001).

Multicolour fluorescent in situ hybridisation (M-FISH) is a karyotyping technique that uses whole chromosome paints (WCP) to label each chromosome a unique colour (Speicher et al, 1996). Use of this technique facilitates the karyotyping of tumour cells and allows the identification of marker chromosomes and complex chromosomal rearrangements that would previously have been uninterpretable. Additionally, the use of colour has opened up the field to noncytogeneticists. Despite these technological advances, acquisition of suitable metaphase spreads is still a problem and consequently much of the work on solid tumours with M-FISH (or the similar technique Spectral Karyotyping (SKY); Schröck et al, 1996) has been carried out using established cell lines. Although useful models for studying cancer, our previous analysis of independently cultured strains of a breast cancer cell line (Bahia et al, 2002) revealed unique abnormalities in each variant, suggesting that cell lines may not provide data as reliable and as clinically relevant as that obtained from primary tumour samples.

To date, 10 NSCLC cell lines (MGH7, A549, A427, BEN, Colo699, D51, D54, D97, D117 and DV-90) and just two primary tumour samples (both squamous cell carcinomas) have been analysed using M-FISH or SKY (Speicher et al, 2000; Gunawan et al, 2001; Luk et al, 2001). These studies, and previous studies using cytogenetic banding (Testa et al, 1994; Sundareshan and Augustus, 
1996; Berker-Karaüzüm et al, 1998) have revealed highly complex cytogenetic changes in the majority of cases, with no common pattern of chromosome rearrangements. Despite this, some translocations have been reported by multiple authors: a $t(3 ; 19)$ was observed in four studies and $t(1 ; 19)$ and $t(1 ; 16)$ in three studies each (Sundareshan and Augustus, 1996; Speicher et al, 2000; Gunawan et al, 2001; Luk et al, 2001). Additionally, isochromosomes of $5 p$ and $8 \mathrm{q}$ are frequently observed in NSCLC and are also seen in other solid tumours.

Here we present results from the analysis of four primary NSCLC tumour samples in short-term culture and two established NSCLC cell lines (COR-L23 and COR-L105) by M-FISH and CGH. To our knowledge, the karyotypes of these two cell lines have not previously been reported. The aim of our study was to examine the gross genomic changes present in order to identify structural and numerical alterations that may warrant further investigation using higher resolution molecular techniques. It is hoped that the identification of such changes may eventually lead to improvements in diagnosis and the identification of prognostic factors for NSCLC.

\section{MATERIALS AND METHODS}

\section{Primary tumour samples}

Samples of fresh lung tumour were obtained from patients undergoing surgery for NSCLC at Castle Hill Hospital. Informed consent was obtained from all patients and local ethical approval granted for the study. All tumour samples were processed on the day of surgery. Tissue samples were cut into pieces approximately $1 \mathrm{~mm}^{3}$ using sterile scalpels and a cell suspension obtained by digestion with $0.5 \mathrm{mg} \mathrm{ml}^{-1}$ type III collagenase (Sigma-Aldrich, Dorset, UK) at $37^{\circ} \mathrm{C}$ with $5 \% \mathrm{CO}_{2}$ for $18-24 \mathrm{~h}$. Cells were pelleted at $200 \mathrm{~g}$ for $4 \mathrm{~min}$ and resuspended in RPMI 1640 medium supplemented with $10 \% \mathrm{vv}^{-1}$ foetal calf serum, $2 \mathrm{mM}$ glutamine, $100 \mathrm{U} \mathrm{ml}^{-1}$ penicillin, $100 \mu \mathrm{g} \mathrm{ml}^{-1}$ streptomycin and $2.5 \mu \mathrm{g} \mathrm{ml}^{-1}$ fungizone (Life Technologies, Paisley, UK) and the suspension was transferred to $25 \mathrm{~cm}^{2}$ tissue culture flasks and incubated at $37^{\circ} \mathrm{C}$ with $5 \% \mathrm{CO}_{2}$. Once cells began to grow in the flasks, the RPMI medium was changed for ACL-4 (Masuda et al, 1991). Flasks were monitored each day for cell growth and the medium changed as required (at least once a week). Characteristics of the primary tumour samples are given in Table 1.

\section{NSCLC cell lines}

Two established NSCLC cell lines were acquired from the European Collection of Cell Cultures (ECACC, Wiltshire, UK) and were fully authenticated prior to distribution. The cell lines were COR-L23 (ECACC No. 92031919; Baillie-Johnson et al, 1985), a large cell carcinoma, and COR-L105 (ECACC No. 92031918), an adenocarcinoma, both established from pleural effusions from

Table I Characteristics and colcemid treatment conditions of the four primary NSCLC samples

\begin{tabular}{|c|c|c|c|c|}
\hline & SCC-I & SCC-2 & AC-I & AC-2 \\
\hline Sex & Male & Male & Female & Male \\
\hline Age (years) & 71 & 76 & 53 & 69 \\
\hline Cancer site & LUL & RUL & RUL & LUL \\
\hline Culture time & 79 days & 3 days & 62 days & 20 days \\
\hline Colcemid & $|0 \mu|$ & $|00 \mu|$ & $200 \mu \mathrm{l}$ & $|50 \mu|$ \\
\hline & $10 \mu \mathrm{g} \mathrm{ml}^{-1}$ & $\mathrm{l} \mu \mathrm{g} \mathrm{ml} l^{-1}$ & $10 \mu \mathrm{g} \mathrm{ml}^{-1}$ & $\mid \mu \mathrm{g} \mathrm{ml}^{-1}$ \\
\hline Treatment & $16 \mathrm{~h}$ & $16 \mathrm{~h}$ & $3 \mathrm{~h}$ & $16 \mathrm{~h}$ \\
\hline
\end{tabular}

$\mathrm{SCC}=$ squamous cell carcinoma; $\mathrm{AC}=$ adenocarcinoma; $\mathrm{LUL}=$ left upper lobe; $\mathrm{RUL}=$ right upper lobe.
Caucasian males. Cell lines were cultured in RPMI 1640 medium supplemented with $10 \% \mathrm{vv}^{-1}$ foetal calf serum, glutamine, penicillin, streptomycin and fungizone (as above).

\section{Preparation of metaphase spreads}

Cell cultures were treated with colcemid (Life Technologies) prior to reaching confluence and incubated at $37^{\circ} \mathrm{C}$. Cell lines received $200 \mu \mathrm{l} 10 \mu \mathrm{g} \mathrm{ml}^{-1}$ colcemid for $1 \mathrm{~h}$; treatment conditions for primary tumour samples are given in Table 1. Cells were harvested and treated with hypotonic solution $(0.075 \mathrm{M} \mathrm{KCl})$ for $20 \mathrm{~min}$, fixed in three changes of fixative solution $(3: 1$, methanol:acetic acid) and stored at $-20^{\circ} \mathrm{C}$ overnight. Chromosome preparations were dropped onto cleaned, humidified standard microscope slides and stored overnight at room temperature. Slides were assessed using phase contrast microscopy to ensure the presence of metaphase spreads of suitable quality before performing M-FISH.

\section{M-FISH}

M-FISH was performed as described previously (Ashman et al, 2002; Bahia et al, 2002) using the SpectraVysion ${ }^{\mathrm{TM}}$ Assay system (Abbott Laboratories, Maidenhead, UK). SpectraVysion consists of a 52-probe mix of WCPs labelled with different combinations of five fluorochromes (SpectrumGold, SpectrumRed, SpectrumGreen, SpectrumAqua and SpectrumFarRed). In total, 24 combinations of no more than three fluorochromes are used, resulting in a unique colour for each chromosome (22 autosomes and two sex chromosomes).

Before the probe was applied, metaphase preparations were enzymatically treated with RNase and pepsin to remove RNA molecules and cytoplasmic proteins. Exact conditions varied between preparations depending on the amount of residual cytoplasm. Slides were fixed in a $1 \%$ formaldehyde solution, dehydrated, denatured in $70 \%$ formamide $/ 2 \times$ saline sodium citrate (SSC) and dehydrated for a second time. A measure of $10 \mu \mathrm{l}$ of SpectraVysion probe was denatured, applied to the slides and incubated at $37^{\circ} \mathrm{C}$ for $72 \mathrm{~h}$ to allow the probe to hybridise to the chromosomes. Following hybridisation, slides were washed in $0.4 \times \mathrm{SSC} / 0.3 \% \mathrm{NP}-40$ (Abbott) at $72^{\circ} \mathrm{C}$ for $2 \mathrm{~min}$ followed by $2 \times$ $\mathrm{SSC} / 0.1 \% \mathrm{NP}-40$ at room temperature for $30 \mathrm{~s}$. Slides were air dried and counterstained with $10 \mu \mathrm{l}$ of $42 \mathrm{ng} \mathrm{ml}^{-1} 4,6$-diamidino-2phenylindole (DAPI) counterstain in antifade (Abbott).

Images of metaphase spreads were captured using a Nikon ${ }^{\circledR}$ E800 epifluorescent microscope equipped with a Ludl 6 position filter wheel and a Photometrics Sensys ${ }^{\mathrm{TM}}$ cooled charge coupled device (CCD) camera. Six images were captured using filter combinations specific for each of the five fluorochromes and DAPI. All metaphases of suitable quality for analysis were captured. Spreads ideally contained long, well spread out chromosomes and did not contain large amounts of cell debris. Images were analysed using the Quips SpectraVysion software (Abbott) by examining each individual colour plane (Red, Gold, Green, Aqua and Far Red) and identifying the chromosomal material present by the combinations of fluorochromes observed. The analysis of a primary squamous cell carcinoma is shown in Figure 1.

A composite karyotype was compiled for each sample using six to nine metaphase spreads. Following ISCN recommendations (ISCN 1995), rearranged chromosomes were included when two or more cells exhibited the same structural aberration. The modal number of each whole or rearranged chromosome was used in the composite karyotype. Translocations were reported in shortened ISCN format as derivative (der) chromosomes, but the break points could not be defined as identification using DAPI banding is difficult and requires cytogenetic expertise. Inversions and small deletions or amplifications are not identifiable using M-FISH. 

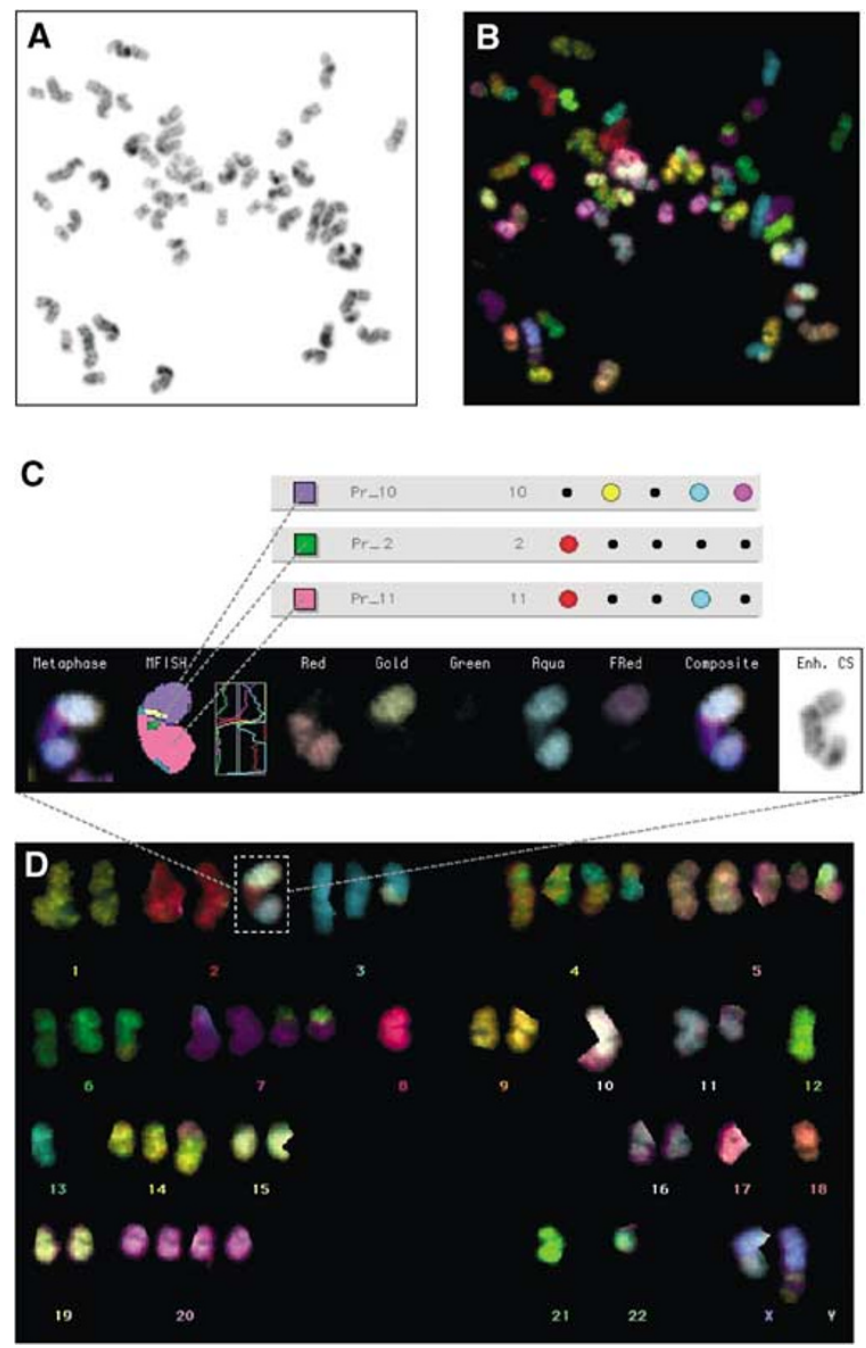

Figure I Analysis of a primary squamous cell carcinoma (SCC-I) by $M$ FISH: the metaphase spread stained with DAPI $(\mathbf{A})$ and the M-FISH probe (B), an example of a translocation involving material originating from chromosomes 10,2 and II (C) and the karyotype of the cell (D). The chromosome view shows (from left to right): the chromosome as it appears in the metaphase spread, the pseudocolours generated by the computer, a graph of the intensity of each fluorochrome along the chromosome axis, the individual colour planes (red, gold, green, aqua and far red), the composite image of all the colours and the chromosome stained with DAPI. This metaphase contains 5 I chromosomes and is one of the seven spreads used in compiling the composite karyotype of the sample (see Table 2).

\section{CGH}

All CGH reagents were obtained from Abbott Laboratories and experiments were performed as described previously (Stafford et al, 1999). Briefly, $400 \mathrm{ng}$ tumour DNA labelled with SpectrumGreen was combined with $200 \mathrm{ng}$ reference DNA labelled with SpectrumRed and $20 \mu \mathrm{g}$ of Cot-1 blocking DNA. This probe mix was ethanol precipitated, resuspended in hybridisation buffer and hybridised to normal human metaphase chromosomes for $72 \mathrm{~h}$ at $37^{\circ} \mathrm{C}$. Slides were washed in $0.4 \times \mathrm{SSC} / 0.3 \% \mathrm{NP}-40$ followed by $2 \times \mathrm{SSC} / 0.1 \% \mathrm{NP}-40$, air dried, and counterstained with $125 \mathrm{ng} \mathrm{ml}^{-1}$ DAPI in antifade. In total, 10 images of metaphase spreads were captured per sample using the same system as for M-FISH and analysed using the Quips CGH Analysis software (Abbott). Losses and gains of DNA sequences were scored whenever the ratio of red:green or green:red fluorescence exceeded thresholds established through hybridisations of differently labelled normal DNA samples ( 0.85 and 1.15 , respectively).

\section{RESULTS}

\section{M-FISH}

The composite karyotype for each sample analysed by M-FISH (see Figure 1) is shown in Table 2. In total, 93 different interchromosomal translocations were observed in the composite karyotypes from the six samples and 17 of these were observed in more than one sample: 14 in two samples and three in three samples (Table 3). Every chromosome was involved in at least one translocation, but six chromosomes $(4,5,8,11,12$ and 19) appeared to be involved particularly frequently (Figure 2). Chromosome 5 was the most frequently involved chromosome, with 38 translocations. Structures believed to be isochromosomes of $5 \mathrm{p}$ were observed in three samples and of $6 p$ and $13 q$ in one sample each.

Primary tumour samples had very complex karyotypes with many structural aberrations, whereas the two cell lines, especially COR-L23, were less complex and harboured only a few translocations (two in COR-L23 and 15 in COR-L105, compared with a mean of 32 in the primary tumour samples).

Numerical abnormalities were difficult to identify due to the complexity of the karyotypes and the involvement of the same chromosome in multiple rearrangements within a single karyotype. However, some recurrent numerical changes of whole chromosomes or chromosome arms were observed: a gain of chromosome 20 (above the ploidy level of the sample) in three samples, additional copies of $5 p$ in two samples (some in the form of $5 \mathrm{p}$ isochromosomes), loss of the $\mathrm{Y}$ chromosome in three of the five male samples and deletions of $3 p$ in two samples.

\section{CGH}

CGH data for five of the six samples (AC-1, AC-2, SCC-2, COR-L23 and COR-L105) were available. The most common areas of loss and gain of DNA sequences and minimal regions of overlap are shown in Table 4 . Other regions of interest include $14 \mathrm{q}$ and $15 \mathrm{q}$, where gains were seen in the two cell lines but not in any of the primary tumour samples (data not shown). The $\mathrm{X}$ and $\mathrm{Y}$ chromosomes were excluded from CGH analysis as samples and reference DNA were not sex-matched.

\section{DISCUSSION}

There is little known about the gross chromosomal aberrations present in solid tumours, mainly due to the difficulty in obtaining metaphase spreads from such samples and the complex nature of the karyotypes, which makes analysis by banding patterns incredibly difficult. We have analysed four primary NSCLC tumours and two established NSCLC cell lines using modern molecular cytogenetic techniques that allow genetic aberrations to be elucidated, which would have been uninterpretable using conventional cytogenetic methods.

The karyotypes of the primary tumour samples were highly complex and contained many structural aberrations, including the involvement of some chromosomes in many different rearrangements within a single karyotype. The established cell lines showed generally less complex karyotypes, but structural alterations were still present. In total, 93 different interchromosomal translocations were observed in the six samples. Due to the genetic instability of cancer cells, many of these could merely be random rearrangements of unstable genetic material. However, 17 translocations were observed in either two or three samples, suggesting that combinations of specific chromosomes may occur nonrandomly. 
Table 2 Composite karyotype for each tumour sample and cell line

\begin{tabular}{|c|c|}
\hline Sample & Composite karyotype \\
\hline $\mathrm{AC}-1$ q & 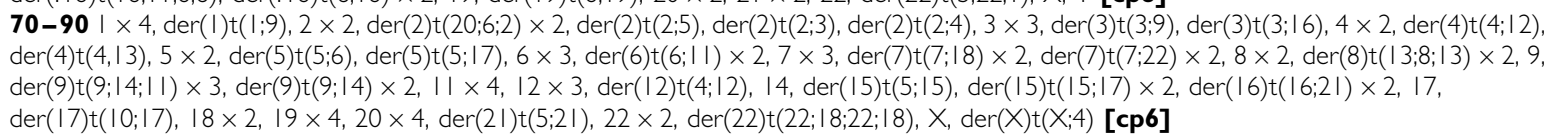 \\
\hline$A C-2 \quad \hat{o}$ & 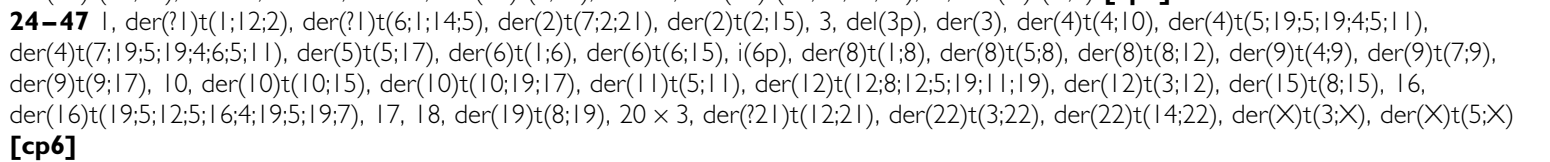 \\
\hline COR-LIO5 (AC) & $\begin{array}{l}\mathbf{1 8 - 3 9} \operatorname{der}(1) t(1 ; 11), \operatorname{der}(1) t(1 ; 6), 2 \times 2, \operatorname{der}(3) t(3 ; 21), \operatorname{der}(3) t(3 ; X ; 4 ; X), 4,5,6,7, \operatorname{der}(\mathbf{7}) \mathbf{t}(\mathbf{7} ; \mathbf{1 0} \mathbf{0}), 8,9,10, \operatorname{der}(\mathbf{1 0}) \mathbf{t}(\mathbf{7} ; \mathbf{1 0} \mathbf{0}) \operatorname{der}(1 \mid) t(5 ; 11), 12, \\
13,14, \operatorname{der}(14) t(8 ; 14), \operatorname{der}(14) t(12 ; 14), 15, \operatorname{der}(15) t(15 ; 12 ; 8), 16, \operatorname{der}(16) t(3 ; 16), 17,18,19, \operatorname{der}(19) t(16 ; 19), 20,21,22 \text { [cp9] }\end{array}$ \\
\hline
\end{tabular}

Bold numbers at the beginning of each karyotype are the range of chromosome numbers for the spreads analysed, numbers in square brackets are the number of spreads used to compile the composite karyotype. The number of each chromosome or altered chromosome given is the modal number. Bold text represents translocations that may be reciprocal.

Table $3 \quad 17$ translocations that were observed in more than one sample by M-FISH and the number of times they were observed primary tumours and cell lines

\begin{tabular}{lccc}
\hline Translocation & $\begin{array}{c}\text { Primary tumour } \\
(\boldsymbol{n}=\mathbf{4})\end{array}$ & $\begin{array}{c}\text { Cell line } \\
(\boldsymbol{n}=\mathbf{2})\end{array}$ & $\begin{array}{c}\text { Total } \\
(\boldsymbol{n}=\mathbf{6})\end{array}$ \\
\hline $\mathrm{t}(5 ; 14)$ & $3^{\mathrm{a}}$ & 0 & 3 \\
$\mathrm{t}(1 ; 6)$ & 2 & 1 & 3 \\
$\mathrm{t}(5 ; 1)$ & 2 & 1 & 3 \\
$\mathrm{t}(3 ; 10)$ & $2^{\mathrm{a}}$ & 0 & 2 \\
$\mathrm{t}(5 ; 22)$ & $2^{\mathrm{a}}$ & 0 & 2 \\
$\mathrm{t}(7 ; 12)$ & $2^{\mathrm{a}}$ & 0 & 2 \\
$\mathrm{t}(5 ; 6)$ & $2^{\mathrm{b}}$ & 0 & 2 \\
$\mathrm{t}(5 ; 17)$ & $2^{\mathrm{b}}$ & 0 & 2 \\
$\mathrm{t}(4 ; 5)$ & 2 & 0 & 2 \\
$\mathrm{t}(4 ; 13)$ & 2 & 0 & 2 \\
$\mathrm{t}(5 ; 12)$ & 2 & 0 & 2 \\
$\mathrm{t}(8 ; 19)$ & 2 & 0 & 2 \\
$\mathrm{t}(X ; 3)$ & 2 & 1 & 2 \\
$\mathrm{t}(X ; 4)$ & 1 & 1 & 2 \\
$\mathrm{t}(3 ; 16)$ & 1 & 1 & 2 \\
$\mathrm{t}(8 ; 12)$ & 1 & 1 & 2 \\
$\mathrm{t}(16 ; 19)$ & 1 & 1 & 2 \\
\hline
\end{tabular}

${ }^{\text {aT }}$ Two squamous cell carcinoma samples. ${ }^{\text {b}}$ Two adenocarcinoma samples.

Of the translocations observed in two samples, only $\mathrm{t}(5 ; 6), \mathrm{t}(8 ; 12)$ and $\mathrm{t}(8 ; 19)$ have been reported by other authors (Gunawan et al, 2001; Speicher et al, 2000). Those translocations appearing in three samples are of particular interest, especially $t(5 ; 14)$, as this rearrangement was observed in three primary tumour samples, rather than in the established cell lines. In a recent study using MFISH, Gunawan et al (2001) recorded the presence of two derivative chromosomes formed by a $t(5 ; 14)$ translocation in a primary squamous cell carcinoma. Two of the three samples in which we observed this translocation were also squamous cell carcinomas, although the samples size is far too small to be able to speculate as to whether this may be a histotype-related change. Gunawan et al (2001) also report a t $(5 ; 11)$ translocation, another of the rearrangements to be identified in three samples in this study. The remaining frequent translocation observed in our study, $t(1 ; 6)$, has also previously been reported by two authors (Luk et al, 2001;
Speicher et al, 2000). Despite the small numbers of samples involved, the fact that these combinations of chromosomes have been reported in more than one study may imply that they could be important in the development of NSCLC. It is not possible to say whether the breakpoints involved in these common translocations are the same in each case. Further investigation of the chromosomes involved will be necessary to ascertain if this is so, and if specific genes located at the breakpoints are perturbed by the rearrangements.

Six chromosomes $(4,5,8,11,12$ and 19) were shown to be involved in rearrangements more often than the other chromosomes. Chromosome 5 was involved particularly frequently, with 38 interchromosomal translocations. In addition, the p-arm of this chromosome was the most frequently gained region as indicated by $\mathrm{CGH}$. The possible formation of $5 \mathrm{p}$ isochromosomes observed by M-FISH is supported by the CGH data, as the two samples harbouring iso $5 p$ for which CGH data are available show a gain of the entire p-arm. Formation of $5 p$ isochromosomes would also require rearrangement of chromosome 5 material, thus further increasing the number of rearrangements involving this chromosome. Speicher et al (2000) reported frequent involvement of chromosomes $1,2,3,11,12$ and 22 in intraand interchromosomal changes. Chromosomes 5, 8 and 19 were observed by these authors to be involved less frequently, and chromosome 4 was involved infrequently in rearrangements. Our data therefore partially support those of Speicher et al (2000), and suggest that in addition to chromosome 5, chromosomes 11 and 12 may be of particular interest. The differences between the two studies may represent true differences between the tumours and cell lines analysed or may be a reflection of the small sample sizes used. This would only be resolved by a larger scale study. Although not all of the frequently rearranged chromosomes have been observed to participate in specific fusions with other chromosomes, the breakpoints involved warrant further investigation to discover if the same loci are involved each time.

The observation of $5 \mathrm{p}$ isochromosomes supports previous reports (Testa et al, 1994; Speicher et al, 2000; Luk et al, 2001). Polysomy of chromosome 20 has also been observed previously in NSCLC (Testa et al, 1994; Berker-Karaüzüm et al, 1998), and loss of the $\mathrm{Y}$ chromosome in males is known to be common in tumour cells. 


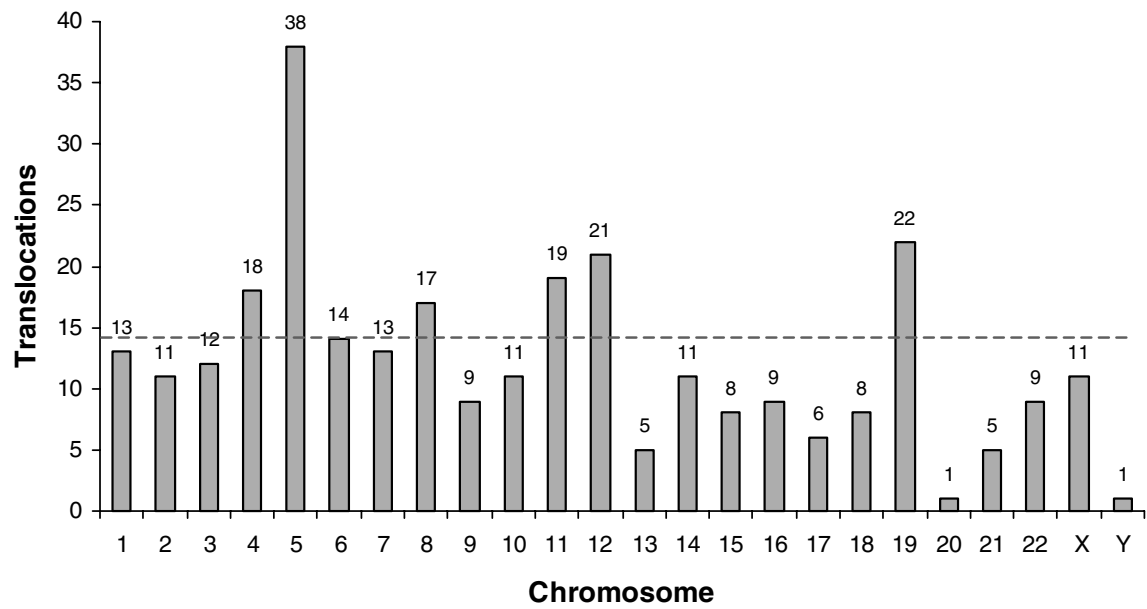

Figure 2 Graphical representation of the total number of interchromosomal translocations for each chromosome observed in the composite karyotypes for four primary NSCLC samples and two cell lines. The dashed line indicates an arbitary cutoff between the six chromosomes, which appear to be frequently involved in translocations and those which are involved less often.

Table 4 Common regions of gain and loss of DNA sequences (including minimal regions of overlap) in primary tumour samples and cell lines observed by $\mathrm{CGH}$

\begin{tabular}{|c|c|c|c|c|}
\hline Region & $\begin{array}{c}\text { Primary } \\
\text { tumour } \\
(n=3)\end{array}$ & $\begin{array}{l}\text { Cell line } \\
(n=2)\end{array}$ & $\begin{array}{c}\text { Total } \\
(n=5)\end{array}$ & $\begin{array}{l}\text { Minimal region } \\
\text { of overlap }\end{array}$ \\
\hline \multicolumn{5}{|l|}{ Gain } \\
\hline $5 p$ & 3 & 2 & 5 & $p||-p \mid 3^{a}$ \\
\hline $3 q$ & 2 & 2 & 4 & $q 13.3-q 25$ \\
\hline $8 q$ & 2 & 2 & 4 & q23 \\
\hline||$q$ & 2 & 2 & 4 & $q 13$ \\
\hline $2 q$ & 2 & I & 3 & $q 22-q 24$ \\
\hline $12 p$ & I & 2 & 3 & $p|| .|-p| \mid .2$ \\
\hline $12 q$ & I & 2 & 3 & $\mathrm{q} 21$ \\
\hline \multicolumn{5}{|l|}{ Loss } \\
\hline $9 p$ & 3 & 2 & 5 & p23 \\
\hline $3 p$ & 2 & 2 & 4 & $p 24-p 25$ \\
\hline $6 q$ & 2 & 2 & 4 & q25-qter \\
\hline $17 p$ & 2 & 2 & 4 & $p|| .|-p| 2$ \\
\hline $22 q$ & 2 & 2 & 4 & $q 13$ \\
\hline $8 p$ & 2 & 1 & 3 & $p 21-p 22$ \\
\hline $10 p$ & 2 & I & 3 & $p 13$ \\
\hline $10 q$ & 2 & I & 3 & q25-qter \\
\hline $19 p$ & 2 & I & 3 & pl3.2 \\
\hline
\end{tabular}

${ }^{a}$ Four out of five samples (including two observed by M-FISH to have iso5p) showed gains of the entire $5 p$ arm.

The chromosome regions identified through CGH as being frequently gained are consistent with published results. Chromosome arms $3 \mathrm{q}, 5 \mathrm{p}$ and $8 \mathrm{q}$, along with $1 \mathrm{q}$ and $7 \mathrm{p}$, have been shown to be commonly over-represented in NSCLC. The minimal region of overlap on $8 \mathrm{q}$ in our study (q23) is the location of the EBAG9/RCAS1 gene, which encodes a cancer cell-surface antigen implicated in immune escape and has recently been shown to be amplified in breast cancer (Tsuneizumi et al, 2001). A potentially important gene located within the minimal region of overlap on 5p (p11-p13) is SKP2 at 5p13. This protooncogene encodes a protein which is associated with the cyclinA/cdk2 complex and is essential for transition into S-phase (Zhang et al, 1995). The minimal region of overlap observed on $11 \mathrm{q}(\mathrm{q} 13)$ is the site of the cyclin D1 gene which is an oncogene implicated in lung cancer. Gains of $11 \mathrm{q}$ have previously been reported in NSCLC by Petersen et al. (1997) and Luk et al.
(2001). The final region gained in four samples was $3 \mathrm{q}$ (minimal region of overlap q13.3-q25). Gains of $3 \mathrm{q}$ have previously been shown to be important in lung cancer, especially $3 \mathrm{q} 25-\mathrm{q} 27$ in squamous cell carcinoma, suggesting that multiple genes within this region may be important for tumorigenesis (Kettunen et al, 2000).

The observation of losses on chromosomes $3 p, 6 q, 9 p$ and $17 p$ is also in agreement with the current body of literature relating to NSCLC (Balsara et al, 1997; Petersen et al, 1997; Björkqvist et al, 1998; Speicher et al, 2000; Luk et al, 2001). Losses of all these regions were observed in either four or five samples in this study. Chromosomes $9 \mathrm{p}$ and $17 \mathrm{p}$ are known to harbour the tumour suppressor genes $p 16$ and $p 53$, respectively, but their locations do not correspond to the minimal regions of overlap identified in this study. Losses of $3 p$, including $3 \mathrm{p} 25$, are known to be frequent in lung cancer. The minimal region of loss observed here (3p24-p25) is in agreement with this. Potentially important genes within this region are retinoic acid receptor beta $(R A R B)$ at $3 \mathrm{p} 24$, which is a nuclear transcription factor thought to limit cell growth by regulating gene expression, and the von Hippel-Lindau (VHL) tumour suppressor gene at $3 p 25$. Losses of $3 p$ and $6 q$ have previously been associated with the metastatic phenotype in both adenocarcinoma and squamous cell carcinoma of the lung (Petersen et al, 2000; Goeze et al, 2002). A further region found to be frequently lost in this study was $22 \mathrm{q}$, with the minimal region of overlap at $\mathrm{q} 13$. The existence of putative tumour suppressor gene(s) in this region involved in breast and colorectal tumorigenesis has been proposed (Castells et al, 2000), but to our knowledge this has not previously been characterised in lung cancer.

In summary, we have demonstrated the power of M-FISH, in combination with CGH, in the study of primary NSCLC and established cell lines. The use of this colour-karyotyping technique has enabled the highly complex genomes of these samples to be analysed in far greater detail than would previously have been possible. Despite the small sample size, we have been able to identify certain chromosomes and chromosomal regions which are frequently involved in structural and numerical aberrations and which may therefore warrant further investigation. The use of higher resolution molecular genetic techniques will enable the specific breakpoints and genes involved in these aberrations to be identified. This in turn is likely to lead to an increased understanding of the aetiology and progression of NSCLC and yield information that can be used to improve patient diagnosis and prognosis. 


\section{REFERENCES}

Ashman JNE, Brigham J, Cowen ME, Bahia H, Greenman J, Lind M, Cawkwell L (2002) Chromosomal alterations in small cell lung cancer revealed by multicolour fluorescent in situ hybridization. Int J Cancer 102: 230-236

Bahia H, Ashman JNE, Cawkwell L, Lind M, Monson JRT, Drew PJ, Greenman J (2002) Karyotypic variation between independently cultured strains of the cell line MCF-7 identified by multicolour fluorescence in situ hybridization. Int J Oncol 20: 489-494

Baillie-Johnson H, Twentyman PR, Fox NE, Walls GA, Workman P, Watson JV, Johnson N, Reeve JG, Bleehen NM (1985) Establishment and characterisation of cell lines from patients with lung cancer (predominantly small cell carcinoma). Br J Cancer 52: 495-504

Balsara BR, Sonoda G, du Manoir S, Siegfried JM, Gabrielson E, Testa JR (1997) Comparative genomic hybridization analysis detects frequent, often high-level, overrepresentation of DNA sequences at $3 q, 5 p, 7 p$ and $8 \mathrm{q}$ in human non-small cell lung carcinomas. Cancer Res 57: 2116-2120

Berker-Karaüzüm S, Lüleci G, Özbilim G, Erdoğan A, Kuzucu A, Demircan A (1998) Cytogenetic findings in thirty lung carcinoma patients. Cancer Genet Cytogenet 100: 114-123

Björkqvist A-M, Husgafvel-Pursiainen K, Anttila S, Karjalainen A, Tammilehto L, Mattson K, Vainio H, Knuutila S (1998) DNA gains in $3 \mathrm{q}$ occur frequently in squamous cell carcinoma of the lung, but not in adenocarcinoma. Genes Chromosom Cancer 22: 79-82

Castells A, Gusella JF, Ramesh V, Rustig AK (2000) A region of deletion on chromosome $22 \mathrm{q} 13$ is common to human breast and colorectal cancers. Cancer Res 60: 2836-2839

Goeze A, Schluns K, Wolf G, Thäsler Z, Petersen S, Petersen I (2002) Chromosomal imbalances of primary and metastatic lung adenocarcinomas. J Pathol 196: 8-16

Gunawan B, Mirzaie M, Schulten H-J, Heidrich B, Füzesi L (2001) Molecular cytogenetic analysis of two primary squamous cell carcinomas of the lung using multicolor fluorescence in situ hybridization. Virchows Arch 439: $85-89$

ISCN (1995) An International System for Human Cytogenetic Nomenclature, Mitelman F (ed) Basel: S. Karger

Kallioniemi A, Kallioniemi O-P, Sudar D, Rutovitz D, Gray JW, Waldman F, Pinkel D (1992) Comparative genomic hybridization for molecular cytogenetic analysis of solid tumours. Science 258: 818-821

Kettunen E, El-Rifai W, Björkqvist A-M, Wolff H, Karjalainen A, Anttila S, Mattson K, Husgafvel-Pursiainen K, Knuutila S (2000) A broad amplification pattern at $3 \mathrm{q}$ in squamous cell lung cancer - a fluorescence in situ hybridization study. Cancer Genet Cytogenet 117: 66-70

Luk C, Tsao M-S, Bayani J, Shepherd F, Squire JA (2001) Molecular cytogenetic analysis of non-small cell lung carcinoma by spectral karyotyping and comparative genomic hybridization. Cancer Genet Cytogenet 125: $87-99$

Masuda N, Fukuoka M, Takada M, Kudoh S, Kusunoki Y (1991) Establishment and characterization of 20 human non-small cell lung cancer cell lines in a serum-free defined medium (ACL-4). Chest 100: $429-438$

Mitelman F (2000) Recurrent chromosome aberrations in cancer. Mutat Res 462: $247-253$

Petersen I, Bujard M, Petersen S, Wolf G, Goeze A, Schwendel A, Langreck H, Gellert K, Reichel M, Just K, du Manoir S, Cremer T, Dietel M, Ried T (1997) Patterns of chromosomal imbalances in adenocarcinoma and squamous cell carcinoma of the lung. Cancer Res 57: 2331-2335

Petersen S, Aninat-Meyer M, Schlüns K, Gellert K, Dietel M, Petersen I (2000) Chromosomal alterations in the clonal evolution to the metastatic stage of squamous cell carcinomas of the lung. Br J Cancer 82: 65-73

Schröck E, du Manoir S, Veldman T, Schoell B, Weinberg J, FergusonSmith MA, Ning Y, Ledbetter DH, Bar-Am I, Soenksen D, Garini Y, Ried $\mathrm{T}$ (1996) Multicolor spectral karyotyping of human chromosomes. Science 273: $494-497$

Speicher MR, Ballard SG, Ward DC (1996) Karyotyping human chromosomes by combinatorial multi-fluor FISH. Nat Genet 12: 368-375

Speicher MR, Petersen S, Uhrig S, Jentsch I, Fauth C, Eils R, Petersen I (2000) Analysis of chromosomal alterations in non-small cell lung cancer by multiplex-FISH, comparative genomic hybridization, and multicolor bar coding. Lab Invest 80: $1031-1041$

Stafford ND, Ashman JNE, MacDonald AW, Ell SR, Monson JRT, Greenman J (1999) Genetic analysis of head and neck squamous cell carcinoma and surrounding mucosa. Arch Otolaryngol Head Neck Surg 125: $1341-1348$

Sundareshan TS, Augustus M (1996) Cytogenetics of non-small cell lung cancer: simple technique for obtaining high quality chromosomes by fine needle aspirate cultures. Cancer Genet Cytogenet 91: 53-60

Testa JR, Siegfried JM, Liu Z, Hunt JD, Feder MM, Litwin S, Zhou J-Y, Taguchi T, Keller SM (1994) Cytogenetic analysis of 63 non-small cell lung carcinomas: recurrent chromosome alterations amid frequent and widespread genomic upheaval. Gene, Chromosom Cancer 11: 178-194

Tsuneizumi M, Emi M, Nagai H, Harada H, Sakamoto G, Kasumi F, Inoue S, Teruhisa K, Nakamura Y (2001) Overrepresentation of the EBAG9 gene at $8 \mathrm{q} 23$ associated with early-stage breast cancers. Clin Cancer Res 7: $3526-3532$

Zhang H, Kobayashi R, Galaktionov K, Beach D (1995) p19Skp1 and p45Skp2 are essential elements of the cyclin A-CDK2 S-phase kinase. Cell 82: $915-925$ 